\title{
Menstrual disorders and their determinants among women with epilepsy
}

This article was published in the following Dove Press journal:

Neuropsychiatric Disease and Treatment

\section{Magdalena Bosak \\ Agnieszka Słowik \\ Wojciech Turaj}

Department of Neurology, Jagiellonian University Medical College, Krakow, Poland
Correspondence: Magdalena Bosak Department of Neurology, Jagiellonian University Medical College,

ul. Botaniczna 3, 3I-503 Krakow, Poland

Tel +48 I2 4248600

Fax +48 I2 4248626

Email magdalena.bosak@uj.edu.pl
Introduction: The purpose of the present study was to assess the prevalence and determinants of menstrual cycle disorders among women with epilepsy.

Materials and methods: The study included consecutive women with epilepsy who visited a university epilepsy clinic. A number of variables, including demographics, characteristics of epilepsy and its treatment, and data related to reproductive health (regularity of menstrual cycle, number of pregnancies and childbirths), were collected from medical records, seizure diaries, and a dedicated questionnaire.

Results: The study involved 271 women with epilepsy. Focal epilepsy was diagnosed in 182 (67.2\%) patients; 108 (39.8\%) women had rare seizures ( $<1$ per year), and 164 patients $(60.5 \%)$ were on monotherapy. Menstrual abnormalities were found in 78 patients $(28.8 \%)$ Independent variables associated with irregular cycle included younger age at onset of epilepsy $(\mathrm{OR}=0.95$ per 1 -year increase; $P=0.008)$, current use of clonazepam $(\mathrm{OR}=5.36 ; P=0.010)$, and chronic use of medication(s) other than antiepileptic drug(s) (AEDs; OR=2.48; $P=0.003$ ). Childbirth rate was low in our cohort ( 0.50 per patient); independent predictors of being childless in studied patients included younger age, presence of menstrual disorders, and greater number of currently used AEDs.

Conclusion: Menstrual disturbances were present in $28.8 \%$ of studied women with epilepsy. Increased prevalence of menstrual abnormalities was associated with epilepsy itself (younger age at onset of epilepsy) and its treatment (ongoing use of clonazepam), as well as with chronic use of medications other than AEDs.

Keywords: menstrual disorders, medications, side effect, women, reproductive health

\section{Introduction}

Reproductive health-related issues are among the most important considerations in women with epilepsy, especially in those treated and followed up for many years since the onset of the disease. Menstrual abnormalities, including irregular menstrual cycle, oligo-, poly-, or amenorrhea, are reported more often in women with epilepsy than in the general population. ${ }^{1}$ The potential causes are likely multifactorial but most consistently include frequent seizures ${ }^{1}$ and the use of specific antiepileptic drugs (AEDs), that is, valproic acid (VPA) ${ }^{1}$ or carbamazepine ${ }^{2}$ and the need for polytherapy. ${ }^{1}$ On the other hand, the rate of menstrual abnormalities was similar regardless of epilepsy type (localization related vs idiopathic generalized epilepsy). ${ }^{1,3,4}$

Although management of pregnant women with epilepsy, teratogenicity of AEDs, and outcome of pregnancy in this subgroup of patients are all well described, the issue of menstrual abnormalities is relatively less known and most data come from several studies performed more than a decade ago.$^{1-7}$ Gaps in evidence are related to the introduction of new AEDs and relative paucity of information related to association between 
menstrual disturbances and factors other than epilepsy or its treatment. Thus, we would like to establish whether any AED (especially newer ones) affects the occurrence of the menstrual irregularities. We were also interested if there was any additional impact of nonneurological comorbidities or chronically used medications, as the prevalence of menstrual abnormalities in general population is influenced by smoking, obesity, and chronic stress. ${ }^{8}$

The purpose of the present study was therefore to assess the prevalence and determinants of menstrual cycle disorders among Polish women with epilepsy.

\section{Materials and methods Patients}

This study included consecutive female patients with epilepsy who visited the tertiary outpatient epilepsy clinic at the Department of Neurology within University Hospital in Kraków between January 2016 and October 2017. Inclusion criteria comprised female sex and the diagnosis of epilepsy according to the International League Against Epilepsy guidelines and classifications. ${ }^{9-11}$ Exclusion criteria comprised pregnancy, current use of steroid hormones (including oral contraceptives), active malignancy, or recent (ie, within 6 months) change of AED(s) used to treat epilepsy. We have also excluded women after menopause.

Protocol of the study complied with principles of Helsinki Declaration and received approval from bioethical committee of the Jagiellonian University of Kraków. Each patient was informed about the aim and methods of the study, and they gave the written informed consent to participate.

\section{Methods}

The study had a cross-sectional design. Data were collected from patients' medical records, containing comprehensive history, results of neurological examination, and results of diagnostic studies.

Each patient treated in our outpatient clinic is required to keep the personal seizure diary with prospective collection of data regarding seizures and medication(s). For the purpose of this particular study, patients were additionally asked to prospectively record the date of the first day of menses and duration of their menstrual period during consecutive 6 months. The raw data were then retrieved and stored in the electronic form during the visit scheduled 6-8 months after the baseline one.

Variables related to epilepsy included age at the diagnosis of epilepsy and the type of epilepsy established according to the data from history, neurological examination, electroencephalography, and neuroimaging (MRI or computed tomography if MRI was contraindicated). The type of epilepsy was retrospectively classified with the terminology used in a recent International League Against Epilepsy position paper on classification of epilepsies (generalized, focal, combined generalized and focal, or unknown) to facilitate future comparisons. ${ }^{12}$ The onset of epilepsy was defined as the occurrence of the first-ever seizure. Frequency of seizures within the year preceding the ongoing visit was established according to the data included in the seizure diaries and categorized into 1) more than one seizure per month; 2) 1-12 seizures per year; or 3) less than one seizure per year (the last one considered as "rare seizures"). The type, number, and daily dose of $\operatorname{AED}(\mathrm{s})$ used at the time of the assessment were noted. The number of previously used AEDs was also noted.

The questionnaire dedicated for this study included questions related to the reproductive health issues. We have noted the age at the menarche and whether the onset of epilepsy preceded the menarche (by recall). The numbers of pregnancies, births (including vaginal deliveries and cesarean sections), and children were recorded as well.

Menses were considered irregular, if any of the following abnormalities occurred at least once during the 6-month follow-up: irregular cycle (cycle length varying more than 4 days from cycle to cycle), oligomenorrhea (cycle length longer than 35 days), polymenorrhea (cycle length shorter than 22 days), or amenorrhea (no menstrual bleeding during 6 months of follow-up).

Using the medical records and interview, we have obtained information on concomitant chronic disorders active at the moment of the assessment. They were classified as heart disorders, diabetes, allergies, gastrointestinal diseases, hypercholesterolemia, endocrine or psychiatric disorders. We have also noted the chronic daily use of any medication unrelated to the management of epilepsy.

\section{Statistical analysis}

Descriptive statistics used numbers and percentages for qualitative variables, as well as means with SD or medians with interquartile ranges for quantitative variables. Chisquared test (or Fisher's exact test, where appropriate) was used to assess the significance of the differences between the qualitative data. Student's $t$-test was used to assess differences between quantitative variables.

Univariate analysis included comparison of recorded variables between groups of patients with regular and irregular menses as well as between patients with and without children. 
Analyses of independent factors that influenced occurrence of irregular menses or having children (dependent variables) were performed by logistic regression modeling. Initial models were built with all the variables that differed at the level of $P<0.1$ in univariate analysis. Models were created using stepwise method (backward selection with determining criterion likelihood ratio for variables selection). A $P$-value $<0.05$ was considered statistically significant for the differences between groups or for variables that entered the final models of logistic regression. All the analyses were performed using Statistica v. 12.5 (StatSoft Inc., Tulsa, OK, USA).

\section{Results}

The study involved 271 women aged between 18 and 49 years who visited the tertiary outpatient epilepsy clinic between January 2016 and October 2017. All patients who fulfilled inclusion criteria and had no exclusion criterion agreed to participate.

Table 1 provides data related to the age of participants, age at the diagnosis of epilepsy, type(s) of seizures, frequency of seizures, the most commonly used AEDs as well

Table I General characteristics of studied women with epilepsy

\begin{tabular}{|l|l|}
\hline Variable & $\mathbf{N}=\mathbf{2 7}$ I \\
\hline Age (years); mean (SD) & $29.6(7.3)$ \\
Age at onset of epilepsy (years); mean (SD) & $14.5(8.5)$ \\
Epilepsy type & \\
$\quad$ Generalized & $74(27.3 \%)$ \\
Focal & $182(67.2 \%)$ \\
Combined (generalized and focal) & $6(2.2 \%)$ \\
Unknown & $9(3.3 \%)$ \\
Frequency of seizures & \\
>I per month & $101(37.3 \%)$ \\
I-I2 per year & $62(22.9 \%)$ \\
<I per year & $108(39.8 \%)$ \\
The most commonly used AEDs (in mono- & \\
or polytherapy) & \\
Valproate & $108(39.9 \%)$ \\
Levetiracetam & $95(35.1 \%)$ \\
Lamotrigine & $73(26.9 \%)$ \\
Carbamazepine & $48(17.7 \%)$ \\
Topiramate & $31(11.4 \%)$ \\
Oxcarbazepine & $26(9.6 \%)$ \\
Clonazepam & $13(4.8 \%)$ \\
Concomitant disorders & \\
Allergies & $23(8.5 \%)$ \\
Gastrointestinal disorders & $8(3.0 \%)$ \\
Endocrine disorders & $32(11.8 \%)$ \\
Psychiatric disorders & $33(12.2 \%)$ \\
Any concomitant disorder & $91(33.6 \%)$ \\
Chronic use of medications other than AED & $78(28.9 \%)$ \\
\hline
\end{tabular}

Abbreviation: AED, antiepileptic drug. as co-occurrence of other chronic diseases and the chronic use of medications other than AEDs.

At the time of the assessment, all patients were treated with at least one AED; 164 patients (60.5\%) were on monotherapy. Polytherapy with two AEDs was used by 77 patients (28.4\%); 26 patients $(9.6 \%)$ were treated with three AEDs and other 4 (1.5\%) used four AEDs. The following AEDs (in alphabetical order) were used at the time of assessment at least by one patient: carbamazepine, clobazam, clonazepam, ethosuximide, gabapentin, lacosamide, lamotrigine, levetiracetam, oxcarbazepine, phenobarbital, phenytoin, primidone, tiagabine, topiramate, valproate, and vigabatrin.

Data on reproductive health-related measures, including age at menarche, age at menopause, prevalence of menstrual abnormalities, as well as numbers of pregnancies and children are shown in Table 2. Menstrual abnormalities, in general, were found in 78 out of the 271 studied patients $(28.8 \%)$. Two patients had primary amenorrhea due to RokitanskyMeyer syndrome and other two had primary amenorrhea because of unknown reason. There were 167 pregnancies in 271 patients ( 0.62 per patient) and 136 children were born to those women ( 0.50 per patient). Majority of patients $(n=186$, $68.6 \%$ ) had no children.

Table 3 shows the differences between women with and without menstrual abnormalities. When compared with women without menstrual abnormalities, those with abnormal menstruation were slightly younger at the time of

Table 2 Reproductive health-related measures among studied patients with epilepsy

\begin{tabular}{|l|l|}
\hline Variable & $\mathbf{N}=\mathbf{2 7}$ I \\
\hline Age at menarche (years); mean (SD) & $13.2(1.7)$ \\
Onset of epilepsy before the menarche & $104(38.5 \%)$ \\
Menstrual abnormalities & $78(28.8 \%)$ \\
Polymenorrhea $(<2$ I days) & 0 \\
Oligomenorrhea $(>35$ days) & $6(2.3 \%)$ \\
Amenorrhea & $4(1.5 \%)$ \\
Number of patients with given number of pregnancies & \\
0 & $181(66.8 \%)$ \\
I & $39(14.4 \%)$ \\
2 & $33(12.2 \%)$ \\
3 & $1 I(4.0 \%)$ \\
4 & $6(2.2 \%)$ \\
5 & $I(0.4 \%)$ \\
Number of patients with given number of children & \\
0 & $186(68.6 \%)$ \\
I & $42(15.5 \%)$ \\
2 & $35(I 2.9 \%)$ \\
3 & $8(3.0 \%)$ \\
Vaginal deliveries & 74 \\
Cesarean sections & 67 \\
\hline
\end{tabular}


Table 3 Comparison of demographic features, characteristics of the epilepsy, and antiepileptic medications between patients with regular and irregular menstrual cycle among studied patients with epilepsy

\begin{tabular}{|c|c|c|c|}
\hline Variable & $\begin{array}{l}\text { Patients with menstrual } \\
\text { abnormalities } \\
(\mathrm{n}=78)\end{array}$ & $\begin{array}{l}\text { Patients without menstrual } \\
\text { abnormalities } \\
(\mathrm{n}=193)\end{array}$ & $P$-value \\
\hline Age (years); mean (SD) & $28.2(6.6)$ & $30.1(7.5)$ & 0.051 \\
\hline Age at onset of epilepsy (years); mean (SD) & II $.6(7.5)$ & $15.6(8.6)$ & $<0.001$ \\
\hline Age at menarche (years); mean (SD) & $12.9(1.6)$ & $13.3(1.7)$ & 0.06 \\
\hline Onset of epilepsy before the menarche & 40 (5I.9\%) & $64(33.2 \%)$ & 0.006 \\
\hline \multicolumn{4}{|l|}{ Epilepsy type } \\
\hline Generalized & $17(2 \mid .8 \%)$ & $57(29.5 \%)$ & 0.19 \\
\hline Focal & $53(67.9 \%)$ & $129(66.8 \%)$ & 0.86 \\
\hline Combined (generalized and focal) & $6(7.7 \%)$ & 0 & $<0.001$ \\
\hline Unknown & $2(2.6 \%)$ & $7(3.6 \%)$ & 0.49 \\
\hline \multicolumn{4}{|l|}{ Frequency of seizures } \\
\hline$>I$ per month & $35(44.9 \%)$ & $66(34.2 \%)$ & 0.10 \\
\hline $1-12$ per year & $20(25.6 \%)$ & $42(21.8 \%)$ & 0.49 \\
\hline$<$ I per year & $23(29.5 \%)$ & $85(44.0 \%)$ & 0.03 \\
\hline \multicolumn{4}{|l|}{ Concomitant disorders } \\
\hline Heart diseases & $2(2.6 \%)$ & $6(3.1 \%)$ & 0.58 \\
\hline Diabetes & I (I.3\%) & 0 & 0.29 \\
\hline Allergies & $9(11.5 \%)$ & $14(7.2 \%)$ & 0.25 \\
\hline Gastrointestinal disorders & $4(5.1 \%)$ & $4(2.1 \%)$ & 0.17 \\
\hline Hypercholesterolemia & $\mathrm{I}(\mathrm{I} .3 \%)$ & 0 & 0.29 \\
\hline Endocrine disorders & II (I4.1\%) & $21(10.9 \%)$ & 0.46 \\
\hline Psychiatric disorders & $12(15.4 \%)$ & $21(10.9 \%)$ & 0.30 \\
\hline Any concomitant disorder & $34(43.6 \%)$ & $57(29.5 \%)$ & 0.03 \\
\hline Chronic use of medications other than AED & $31(39.7 \%)$ & $47(24.5 \%)$ & 0.01 \\
\hline \multicolumn{4}{|l|}{ Number of currently used AEDs } \\
\hline Monotherapy & $46(59.0 \%)$ & $118(61.1 \%)$ & 0.74 \\
\hline Two drugs & $20(25.6 \%)$ & $57(29.5 \%)$ & 0.52 \\
\hline Three drugs & $9(11.5 \%)$ & $17(8.8 \%)$ & 0.49 \\
\hline Four drugs & $3(3.8 \%)$ & I (0.5\%) & 0.07 \\
\hline \multicolumn{4}{|l|}{ Currently used AEDs } \\
\hline Valproic acid & $36(46.1 \%)$ & $72(37.3 \%)$ & 0.18 \\
\hline Lamotrigine & $25(32.0 \%)$ & 48 (24.9\%) & 0.23 \\
\hline Levetiracetam & $24(30.8 \%)$ & 7I (36.8\%) & 0.35 \\
\hline Ethosuximide & 0 & $4(2.1 \%)$ & 0.51 \\
\hline Topiramate & 9 (I I.5\%) & $22(11.4 \%)$ & 0.97 \\
\hline Clonazepam & 9 (I I.5\%) & $4(2.1 \%)$ & 0.002 \\
\hline Phenobarbital & 0 & $2(1.0 \%)$ & 0.51 \\
\hline Carbamazepine & 12 (I5.4\%) & $36(18.6 \%)$ & 0.52 \\
\hline Oxcarbazepine & $8(10.2 \%)$ & $18(9.3 \%)$ & 0.81 \\
\hline Tiagabine & I (I.3\%) & I (0.5\%) & 0.49 \\
\hline Phenytoin & 0 & I (0.5\%) & 0.71 \\
\hline Gabapentin & 0 & $3(1.5 \%)$ & 0.36 \\
\hline Vigabatrin & $2(2.6 \%)$ & 0 & 0.08 \\
\hline Lacosamide & $2(2.6 \%)$ & $4(2.1 \%)$ & 0.55 \\
\hline Primidone & 0 & I (0.5\%) & 0.71 \\
\hline Clobazam & $3(3.8 \%)$ & 3 (I.5\%) & 0.23 \\
\hline
\end{tabular}

Abbreviation: AED, antiepileptic drug.

the assessment and were younger at the onset of epilepsy. Patients with irregular menstrual cycle were more likely to have the onset of epilepsy before menarche; they were also younger when menarche occurred. No difference between those two groups was found regarding the prevalence of specific concomitant disorders but women with menstrual abnormalities were more likely to have one of the recorded concomitant disorder and were more likely to chronically use medication(s) other than AEDs. Patients with irregular menstrual cycle used clonazepam more frequently than their counterparts with regular cycle and were less likely to have rare seizures (less than one per year). Otherwise, no specific medication or use of monotherapy or polytherapy differentiated those two groups. 
Table 4 Comparison of women with and without children among studied patients with epilepsy

\begin{tabular}{|c|c|c|c|}
\hline Variable & $\begin{array}{l}\text { Patients who have } \\
\text { children } \\
(n=85)\end{array}$ & $\begin{array}{l}\text { Patients who do not } \\
\text { have children } \\
(n=I 86)\end{array}$ & $P$-value \\
\hline Age (years); mean (SD) & $35.6(6.3)$ & $26.8(6.0)$ & $<0.001$ \\
\hline Age at onset of epilepsy (years); mean (SD) & $17.6(9.9)$ & $13.0(7.4)$ & $<0.001$ \\
\hline Age at menarche (years); mean (SD) & $13.3(1.6)$ & I3.I (I.7) & 0.38 \\
\hline Onset of epilepsy before the menarche & $25(29.8 \%)$ & $79(42.5 \%)$ & 0.04 \\
\hline Menstrual abnormalities & $14(16.5 \%)$ & $64(34.4 \%)$ & 0.002 \\
\hline \multicolumn{4}{|l|}{ Epilepsy type } \\
\hline Generalized & $18(21.2 \%)$ & $56(30.1 \%)$ & 0.13 \\
\hline Focal & $63(74.1 \%)$ & $119(64.0 \%)$ & 0.10 \\
\hline Combined (generalized and focal) & 0 & $6(3.2 \%)$ & 0.10 \\
\hline Unknown & $4(4.7 \%)$ & $5(2.7 \%)$ & 0.30 \\
\hline \multicolumn{4}{|l|}{ Frequency of seizures } \\
\hline$>I$ per month & $33(38.8 \%)$ & $68(36.6 \%)$ & 0.72 \\
\hline $1-12$ per year & $21(24.7 \%)$ & $4 \mathrm{I}(22.0 \%)$ & 0.63 \\
\hline$<$ I per year & 31 (36.5\%) & 77 (4I.4\%) & 0.15 \\
\hline Monotherapy & 45 (52.9\%) & 119 (64.0\%) & 0.08 \\
\hline
\end{tabular}

Table 4 shows comparison of women with epilepsy who have or do not have children. Childless patients were younger at the time of assessment and at the time of epilepsy onset. They were less likely to have regular menstrual cycle as well and more often had onset of epilepsy before their menarche.

Multivariate analysis revealed three independent variables associated with menstrual abnormalities, ie, younger age at onset of epilepsy, current use of clonazepam, and chronic use of medication(s) other than AEDs (see Table 5 for details).

Multivariate analysis of variables associated with having children revealed three independent predictors, that is, younger age, smaller number of currently used AEDs, and lacking menstrual cycle abnormalities (see Table 6 for details).

\section{Discussion}

The study revealed the presence of menstrual abnormalities in more than one-fourth of studied Polish women with epilepsy. We have also shown that not only epilepsy or its treatment but also concomitant nonneurological disorders (or, alternatively, chronic use of medications other than AEDs) are associated with increased prevalence of menstrual irregularity in this cohort of patients.

Prevalence of menstrual abnormalities among women with epilepsy in previously published studies is quite divergent. The methodological factors affecting its values include population studied and definition of menstrual irregularity, among others. Most studies on this topic involved selected patients with either focal ${ }^{6,13,14}$ or primary generalized epilepsy. ${ }^{5}$ They comprised at most 100 patients and revealed presence of menstrual abnormalities in 20\%-33.3\% of subjects. Several studies that used unselected samples of women with various types of epilepsy were published in 1990s or early 2000s. Isojärvi et al ${ }^{15}$ found menstrual abnormalities in $20 \%$ of 238 women with various types of epilepsy seen in an outpatient clinic. A similar rate $(19.6 \%$ of women with irregular menstruation and/or hirsutism among 472 evaluated patients) was found in a most recent Indian study. ${ }^{4}$ Murialdo et $\mathrm{l}^{3}$ noted menstrual abnormalities (defined as a secondary amenorrhea, oligo- or polymenorrhea) in

Table 5 Independent factors associated with menstrual abnormalities in studied women with epilepsy

\begin{tabular}{|c|c|c|c|c|}
\hline Variables $^{\mathbf{a}}$ & Standard error & Wald statistics & $P$-value & OR $(95 \% \mathrm{Cl})$ \\
\hline Chronic use of medication(s) other than AED & 0.30 & 8.75 & 0.003 & $2.48(1.35-4.53)$ \\
\hline Age at onset of epilepsyc & 0.02 & 7.18 & 0.008 & $0.95(0.91-0.99)$ \\
\hline Current use of clonazepam & 0.65 & 6.58 & 0.010 & $5.36(1.48-19.45)$ \\
\hline
\end{tabular}

Notes: $\chi^{2}$ test $=29.9 ; P<0.001$. ${ }^{a}$ The following variables were subsequently removed from the model with the backward elimination procedure: current use of vigabatrin $(P=0.66)$, age at menarche $(P=0.59)$, onset of epilepsy before menarche $(P=0.90)$, number of $A E D s$ in current use $(P=0.33)$, type of epilepsy $(P=0.30)$, frequency of seizures $(P=0.18)$, and age $(P=0.1 \mathrm{I})$. 'When "chronic use of medication(s) other than AED" was replaced by the "presence of any chronic disorder", the latter one was also an independent predictor of menstrual abnormalities ( $P=0.005$; OR: $2.30,95 \% \mathrm{Cl}$ : I.28-4.14). ${ }^{\circ} \mathrm{OR}$ per I-year increase.

Abbreviation: AED, antiepileptic drug. 
Table 6 Independent factors associated with having children in studied women with epilepsy

\begin{tabular}{|l|l|l|l|l|}
\hline Variables $^{\mathrm{a}}$ & Standard error & Wald statistics & $\boldsymbol{P}$-value & OR (95\% Cl) \\
\hline Age $^{\mathrm{b}}$ & 0.03 & 58.9 & $<0.00 \mathrm{I}$ & $1.24(\mathrm{I.18-1.32)}$ \\
Menstrual abnormalities & 0.39 & 3.93 & 0.047 & $0.46(0.21-0.99)$ \\
Number of currently used AEDs & 0.25 & 3.93 & 0.047 & $0.61(0.38-0.99)$ \\
\hline
\end{tabular}

Notes: $\chi^{2}$ test=101.9; $P<0.001$. ${ }^{a}$ The following variables were subsequently removed from the model with the backward elimination procedure: onset of epilepsy before menarche $(P=0.73)$, type of epilepsy $(P=0.5 \mathrm{I})$, frequency of seizures $(P=0.5 \mathrm{I})$, and age at onset of epilepsy $(P=0.29)$. ${ }^{\mathrm{b}} \mathrm{OR}$ per $\mathrm{I}$-year increase.

Abbreviation: $A E D$, antiepileptic drug.

$21.8 \%$ out of 101 women with epilepsy. Higher rates of menstrual irregularities were reported in two other Scandinavian studies - Löfgren et $\mathrm{al}^{7}$ found them in $35 \%$ of women with epilepsy and Svalheim et al noted such abnormalities even in $48 \%$ of patients (compared with very high rate of $30.7 \%$ among controls). ${ }^{1}$ The rate of women with menstrual abnormalities in our study (28.8\%) is therefore in the middle of the range found in the previous studies.

We did not use a case-control design, so it is impossible to state clearly that the rate of irregular cycles found in our study is higher than that seen among women without epilepsy. However, in majority of studies that included control groups, rates of women with irregular menses were significantly higher among patients with epilepsy. ${ }^{1,14}$

Independent factors associated with irregular menstruation among studied women with epilepsy included younger age at onset of epilepsy, treatment with clonazepam, and presence of concomitant nonneurological chronic diseases.

Younger age at onset of epilepsy as a predictor of menstrual abnormalities is most probably related to the early impact of either epilepsy itself or its treatment on the complex neuroendocrine regulation of menstrual cycle as reviewed recently by Pennel. ${ }^{16}$ According to Herzog et al, ${ }^{14}$ both interictal epileptiform discharges and use of enzymeinducing AED lead to alterations of hypothalamo pituitary regulation of gonadal secretion. We can only speculate that the early onset of epilepsy might affect the development of normal functioning of hypothalamopituitary-gonadal axis at the most vulnerable moment. In line with this, we have also noted greater prevalence of menstrual disorders in patients with the onset of epilepsy preceding menarche (in univariate analysis only). On the other hand, Svalheim et $\mathrm{al}^{1}$ did not observe any association between age at onset (or duration of epilepsy) and rate of menstrual disorders among women with epilepsy evaluated in population-based study.

Clonazepam is an AED rarely used in chronic management of epilepsy. In our institution, it is used to treat some patients with drug-resistant epilepsy. To the best of our knowledge, there are no data that may suggest the pathomechanistic association between the chronic use of benzodiazepines (including clonazepam) and subsequent menstrual abnormalities. In our opinion, it is more likely that the use of clonazepam in our cohort was a marker of more severe epilepsy in general and this characteristic might influence the greater prevalence of menstrual disorders in women taking clonazepam. On the other hand, neither frequent seizures nor number of AEDs could substitute treatment with clonazepam in multivariable logistic regression model. It may suggest some importance of clonazepam outside its association with more severe epilepsy.

It is widely known that the use of VPA is a widely accepted risk factor for hyperandrogenism, polycystic ovarian syndrome, and anovulation among women with epilepsy $y^{15,17}$ but contrary to some previous studies, ${ }^{1}$ we did not find an independent role of VPA as a medication causing menstrual disorders.

The study somehow provided reassuring findings related to the use of newer AEDs and risk of menstrual abnormalities. We did not note any significant difference in the rate of irregular menstruation among patients who used lamotrigine, levetiracetam, lacosamide, or topiramate. It is worthy to note that most of the previous studies did not report patients using topiramate, levetiracetam, or lacosamide because they had been published before any meaningful experience with those AEDs was accumulated.

Childbirth rates are thought to be lower among women with epilepsy than in general population ${ }^{18,19}$ but this notion was challenged in some other population-based studies. ${ }^{20,21}$ We did not use a case-control design. Thus, we can only compare the parity calculated for the studied population with the parity in Polish population which was 1.29 in 2015. ${ }^{22}$ Of note, two out of three independent factors associated with being childless in our sample (younger age and irregularity of menstrual cycle) were not related directly to the epilepsy itself. Women in Poland tend to postpone the decision on conception to older age (median age at the first childbirth was 22.7 in 1990, 23.7 in 2000, and 27.6 in 2015), ${ }^{22}$ which might be the reason for smaller parity among studied patients with epilepsy in whom young women were quite prevalent. The third independent variable - the number of currently used AEDs - may 
be viewed as the marker of more severe epilepsy with all its consequences, including individual decisions driven by the patients' concerns about outcome of pregnancy and perceived risks for the well-being of a child. In line with this explanation, it was shown previously that one-third of women affected with epilepsy did not consider having children because of their epilepsy. ${ }^{23}$ Taken together, these factors along with the irregular menstruation might partially explain the relatively low childbirth rates among Polish patients with epilepsy but this notion should be considered as very preliminary because our study was not a population-based one.

We acknowledge several limitations related to our findings and their interpretation. First, the cohort of studied patients involved women followed up in tertiary epilepsy clinic and may be not representative of general population of female patients with epilepsy. It should be noted, however, that we have included consecutive patients with epilepsy without exclusions related to any of the characteristics of the disease. Our primary goal was to evaluate the prevalence of menstrual disorders among largely unselected group of patients with epilepsy. Consequently, our exclusion criteria were minimal and did not include specific causes of those abnormalities. We did not perform formal gynecological and endocrinological assessments; so, the relative contribution of endometriosis of polycystic ovary syndrome, known to be associated with dysmenorrhea, ${ }^{24,25}$ could not be established in the present study. In our opinion, the disentanglement of the complex associations between epilepsy, its treatment, polycystic ovary syndrome, and menstrual abnormality might be extremely difficult, as those relations are likely multidirectional.

Second, our study did not comprise the control group. Thirdly, the definition of "other chronic diseases" was rather general and might be viewed as too simplistic but the proportion of patients who chronically used any medications unrelated to their epilepsy was considered as fair approximation of the importance of their chronic diseases. As expected, it was similar to the proportion of the patients with concomitant disorders and, indeed, did similarly well when put into the model of independent predictors instead of "any concomitant disorder" (see Table 5).

Our results stress the importance of other, nonneurological disorders (or their treatment) as the predictor of menstrual abnormalities; it is suggested that the use of medications other than AED or presence of chronic disorders other than epilepsy should be included in the differential diagnosis of potential causes of menstrual disorders. It is our impression that the occurrence of menstrual abnormalities in women with epilepsy treated with AED is too often attributed to epilepsy or its treatment without broader assessment of other causes. Meanwhile, some lifestyle-related problems, for example, obesity, seem to affect the prevalence of menstrual disorders. As reviewed recently by Seif et $\mathrm{al}^{26}$ obesity itself is associated with the increased frequency of menstrual disorders due to several hormonal abnormalities (ie, increased concentrations of testosterone and lower concentrations of sex hormonebinding globulin, as well as increased frequency of luteinizing hormone pulses). We did not calculate body mass index or other measures of obesity, so it is impossible to draw direct conclusions about the significance of obesity as a potential risk factor for menstrual abnormalities in our cohort. Given the potential importance of this association, the future studies should evaluate these relationships in details.

The association between epilepsy and menstrual disorders is also likely to be bidirectional. Although our study focused on the prevalence of menstrual abnormalities and we did not assess the level of sex hormones throughout the cycle, it is worthy to point to the plausible relation of anovulatory cycles with the increased frequency of generalized tonic-clonic seizures in women serving as their own controls. ${ }^{27}$ Thus, it may occur that the menstrual abnormalities (specifically, anovulation) due to factors unrelated to epilepsy itself might affect the severity of epilepsy, leading to confusion between cause and effect.

Irregular menstrual cycle might have a potential significance beyond the traditional association with decreased fertility or neuroendocrine abnormalities secondary to epilepsy or its treatment. For example, it may independently increase the risk of coronary heart disease which was shown in a prospective study. ${ }^{28}$ Thus, the information on reproductive health-related issues should be a part of a routine assessment in women with epilepsy. The increased awareness of the presence of menstrual abnormalities among women with epilepsy might be the first step toward the intervention, for example, modification of treatment. It was shown recently that the menstrual disturbances noted in women who initially used VPA are reversible when VPA is switched to lamotrigine. ${ }^{29}$ Future studies should bring more unequivocal findings related to the potential interventions that might improve quality of life among women with epilepsy who suffer from menstrual irregularity and its consequences.

\section{Conclusion}

Menstrual disturbances were present in $28.8 \%$ of studied women with epilepsy. Increased prevalence of menstrual abnormalities was associated with epilepsy itself (younger age at onset of epilepsy) and its treatment (ongoing use of 
clonazepam), as well as with chronic use of medications other than AEDs.

\section{Acknowledgment}

Krakowskie Towarzystwo Społeczno-Gospodarcze funded publishing of the manuscript.

\section{Disclosure}

MB received honoraria for publications from Sanofi; honoraria for lectures, travel expenses and conference fees from Sanofi, Adamed, Teva Pharmaceutical, Neuraxpharm, Glenmark, and UCB Pharma. AS received honoraria for lectures from Bayer, Boehringer Ingelheim, Novartis, Polpharma, Bristol-Myers Squibb, Novartis, Biogen, Teva Pharmaceutical, and Medtronic; for the participation in advisory meetings from Bayer, Boehringer Ingelheim, and Novartis. WT received honoraria for publications from Sanofi-Genzyme; honoraria for lectures, travel expenses, and conference fees from Shire and CSL Behring.

\section{References}

1. Svalheim S, Taubøll E, Bjørnenak T, et al. Do women with epilepsy have increased frequency of menstrual disturbances? Seizure. 2003; 12(8):529-533.

2. Isojärvi JI, Laatikainen TJ, Pakarinen AJ, Juntunen KT, Myllylä VV. Menstrual disorders in women with epilepsy receiving carbamazepine. Epilepsia. 1995;36(7):676-681.

3. Murialdo G, Galimberti CA, Magri F, et al. Menstrual cycle and ovary alterations in women with epilepsy on antiepileptic therapy. J Endocrinol Invest. 1997;20(9):519-526.

4. Sahota P, Prabhakar S, Kharbanda PS, et al. Seizure type, antiepileptic drugs, and reproductive endocrine dysfunction in Indian women with epilepsy: a cross-sectional study. Epilepsia. 2008;49(12):2069-2077.

5. Bilo L, Meo R, Nappi C, et al. Reproductive endocrine disorders in women with primary generalized epilepsy. Epilepsia. 1988;29(5): 612-619.

6. Herzog AG, Friedman MN. Menstrual cycle interval and ovulation in women with localization-related epilepsy. Neurology. 2001;57(11): 2133-2135.

7. Löfgren E, Mikkonen K, Tolonen U, et al. Reproductive endocrine function in women with epilepsy: the role of epilepsy type and medication. Epilepsy Behav. 2007;10(1):77-83.

8. Bae J, Park S, Kwon JW. Factors associated with menstrual cycle irregularity and menopause. BMC Womens Health. 2018;18(1):36.

9. Commission on Classification and Terminology of International League Against Epilepsy. Proposal for revised classification of epilepsies and epileptic syndromes. Epilepsia. 1989;30(4):389-399.

10. Commission on Epidemiology and Prognosis, International League Epilepsia. 1993;34(4):592-596. Against Epilepsy. Guidelines for epidemiologic studies on epilepsy.

11. Fisher RS, Acevedo C, Arzimanoglou A, et al. ILAE official report: a practical clinical definition of epilepsy. Epilepsia. 2014;55(4): 475-482.

12. Scheffer IE, Berkovic S, Capovilla G, et al. ILAE classification of the epilepsies: position paper of the ILAE Commission for Classification and Terminology. Epilepsia. 2017;58(4):512-521.

13. Herzog AG, Seibel MM, Schomer DL, Vaitukaitis JL, Geschwind N. Reproductive endocrine disorders in women with partial seizures of temporal lobe origin. Arch Neurol. 1986;43(4):341-346.

14. Herzog AG, Coleman AE, Jacobs AR, et al. Interictal EEG discharges, reproductive hormones, and menstrual disorders in epilepsy. Ann Neurol. 2003;54(5):625-637.

15. Isojärvi JI, Laatikainen TJ, Pakarinen AJ, Juntunen KT, Myllylä VV. Polycystic ovaries and hyperandrogenism in women taking valproate for epilepsy. N Engl J Med. 1993;329(19):1383-1388.

16. Pennell PB. Hormonal aspects of epilepsy. Neurol Clin. 2009;27(4): 941-965.

17. Isojärvi JI, Taubøll E, Herzog AG. Effect of antiepileptic drugs on reproductive endocrine function in individuals with epilepsy. CNS Drugs. 2005;19(3):207-223.

18. Artama M, Isojärvi JI, Raitanen J, Auvinen A. Birth rate among patients with epilepsy: a nationwide population-based cohort study in Finland. Am J Epidemiol. 2004;159(11):1057-1063.

19. Schupf N, Ottman R. Reproduction among individuals with idiopathic/ cryptogenic epilepsy: risk factors for reduced fertility in marriage. Epilepsia. 1996;37(9):833-840.

20. Veiby G, Daltveit AK, Engelsen BA, Gilhus NE. Pregnancy, delivery, and outcome for the child in maternal epilepsy. Epilepsia. 2009; 50(9):2130-2139.

21. Olafsson E, Hauser WA, Gudmundsson G. Fertility in patients with epilepsy: a population-based study. Neurology. 1998;51(1):71-73.

22. Central Statistical Office. Demographic Yearbook of Poland. Warsaw: The Central Statistical Office; 2017:283-287.

23. Crawford P, Hudson S. Understanding the information needs of women with epilepsy at different lifestages: results of the 'Ideal World' survey. Seizure. 2003;12:502-507.

24. Lagana AS, Rosetti P, Buscema M, et al. Metabolism and ovarian function in PCOS women: a therapeutic approach with inositols. Int J Endocrinol. 2016;2016:6306410.

25. Laganà AS, Vitale SG, Salmeri FM, et al. Unus pro omnibus, omnes pro uno: a novel, evidence-based, unifying theory for the pathogenesis of endometriosis. Med Hypotheses. 2017;103:10-20.

26. Seif MW, Diamond K, Nickkho-Amiry M. Obesity and menstrual disorders. Best Pract Res Clin Obstet Gynaecol. 2015;29(4):516-527.

27. Herzog AG, Fowler KM, Sperling MR, et al. Variation of seizure frequency with ovulatory status of menstrual cycles. Epilepsia. 2011; 52(10):1843-1848.

28. Solomon CG, Hu FB, Dunaif A, et al. Menstrual cycle irregularity and risk for future cardiovascular disease. J Clin Endocrinol Metab. 2002;87(5):2013-2017.

29. Sidhu HS, Srinivasa R, Sadhotra A. Evaluate the effects of antiepileptic drugs on reproductive endocrine system in newly diagnosed female epileptic patients receiving either Valproate or Lamotrigine monotherapy: a prospective study. Epilepsy Res. 2018;139:20-27.

\section{Dovepress}

\section{Publish your work in this journal}

Neuropsychiatric Disease and Treatment is an international, peerreviewed journal of clinical therapeutics and pharmacology focusing on concise rapid reporting of clinical or pre-clinical studies on a range of neuropsychiatric and neurological disorders. This journal is indexed on PubMed Central, the 'PsycINFO' database and CAS, and is the official journal of The International Neuropsychiatric Association (INA). The manuscript management system is completely online and includes a very quick and fair peer-review system, which is all easy to use. Visit http://www.dovepress.com/testimonials.php to read real quotes from published authors. 